\title{
Mechanical and the effect of oil absorption on tribological properties of carbon- based brake pad material
}

\author{
Oluwatoyin Joseph Gbadeyan, T. P. Mohan, K. Kanny \\ Composite Research Group, Department of Mechanical Engineering, Durban University of Technology, \\ Durban, South Africa \\ Corresponding author: Oluwatoyin Joseph Gbadeyan (toyin2good@gmail.com)
}

\begin{abstract}
This research focuses on the mechanical and effect of oil absorption on the tribological properties of carbonbased brake pad material (CBP). Carbon-based materials, including those at a nanosize, are combined for developed brake pad material. The mechanical properties related to wear properties such as compression strength, stiffness, hardness, and absorption properties were determined. The effect of oil absorption on the tribological properties of carbon-based materials was investigated. The obtained properties are compared with that of a ceramic-made brake pad (commercial). The experimental results show that the mechanical and absorption properties of the developed brake pad material varied with the combination and quantity of additives used to develop each brake pad material. CBP material offered higher performance than ceramic-made brake pads. The CBP material showed a higher shear strength of about $110 \%, 51 \%$ enhanced compressive strength, 35\% greater modulus, comparative statistical hardness, $98 \%$ lesser water intake, and $97 \%$ oil absorption rate than ceramic made brake pad. The tribological properties of friction material after soaked in oil proved that absorption properties affect tribological properties of brake pads, which can be attributed to the oil content in the material system. The effect of oil uptakes on wear rate and friction of the commercial brake pad was higher than CBP materials, implying that the loading of carbonbased materials is a viable way to reduce absorption rate, which helps in increasing brake pad performance. The improved properties are suggestive of materials combinations that may be used to develop brake pad materials.
\end{abstract}

Keywords: Brake pad materials, Carbon-based additives, Mechanical properties, Absorption properties, and Nanofiller

\section{Introduction}

The braking system requirement for a brake pad required innovative material development technology to provide solutions for one of the critical parts of a moving vehicle. The technical performance of this pad depends on several factors, including but not limited to the tribological, physical, and mechanical properties of selected materials [1 -3]. Moreover, research has proved that a single element cannot fulfill all brake pad requirements since the different function is required in the friction material formation [4]. Similarly, the selection of composite ingredients for pad application depends not only on their function but also on the ingredient cost, processability, availability, and the latest blending techniques, including dimension stability, preforming capability, and mixing [5].

Consequently, researchers have combined more than two composite ingredients and scrutinized each additive. These components are combined and investigated to determine specific properties' suitability to contribute before considered for tribological product applications [6-12]. It was discovered that a combination of some composite ad- ditives offered a positive synergistic property that meets major requirements for friction material $[8,13,14]$. These composite materials have been categorized into metallic, semi-metallic, and non-metallic material, and most used to produce friction materials for many decades [15-17].

Furthermore, these materials (polymeric material, fiber, and fillers), both inorganic and organic, are combined as binders, friction modifiers, reinforcements, and fillers, which are the essential compositions for friction materials developments [7, 12, 18-21]. However, friction material made with metallic particles has been confirmed to be expensive, consistently abrade the rotor, and cause excessive noise when functioning. The non-metallic material commonly used include but is not limited to synthetic or natural fiber-filled ceramics and carbon-based composites. Nevertheless, carbon-based fiber/filler-reinforced hybrid composite has been proven to have superior tribological properties due to their ability to form a catenation, producing composite with improved properties [22, 23].

Carbon-based additives such as graphite, carbonnanotube, silicon carbide, and carbon fiber have commonly 
used a as particle at micro or nanoscales fillers to fabricate friction material due to their improved mechanical properties, prevent corrosion in Fe-additives, enhance fade temperatures, and mechanical contributors to substitute the function of asbestos in friction material [22, 24]. However, Kumar et al. [25] confirmed that metallic fillers are vital additives in friction material due to multiple functions such as strength improvement, absorption of frictional heat generated at extreme temperature, and thermal stability. However, large loading of this metallic fiber in friction material often raises thermal conductivity, affecting other performance such as wear, friction, and fade resistance [26, 27].

Besides, carbon-based additives, such as graphite and carbon fiber, is multifunctional filler that could replace metallic fiber as they promote cross-linking, modify mechanical strength and stiffness, and offer better heat absorption properties, and enhances tribological properties $[24,28,29]$. Studies shown that friction material must have at least one solid lubricant to play a complementary role in reducing fade, wear, creep groan and stabilize friction, in which several additives such as metal sulphite, friction dust, zirconium silicate, antimony trisulfide, graphite, and coke have been used for this purpose [5, 18, 30, 31] Amongst the solid lubricant that serves as internal lubricate in friction material mentioned above, graphite is commonly used due to better thermal stability and the ability to form self-sustaining layers that stabilize the coefficient of friction and wear rate [31,32]. Carbon nanotubes are another multifunctional additive in friction material. Several studies claimed that loading carbon nanotube improves mechanical, thermal, and tribological properties of composite material; this fact made an additive choice for friction material $[15,23,28,29]$.

Moreover, the polymer primarily functions as a binder that forms another vital component of friction material. It provides rigidity, excellent bonding arrangements for various brake pad material ingredients, and maintains structural inclusiveness when subjected to mechanical and thermal stresses [33-35], according to Imaekhai et al. and Blau et al.[18, 36, 37] phenolic resins and modified resin include cresol, epoxy, linseed oil, boron rubber, and PVC is the typical binder used for the brake pad, which is used to modify brake pad bonding characteristics and heat resistance at a very high temperature [18].

Among this additive, the phenolic resin and the modified resin are perhaps the most common binder to reduce fade and maintain the structural stability of the brake pad while functioning under extreme conditions. However, Nagesh et al. [38] asserted that phenolic resin possesses a brittle nature, highly toxic, low impact resistance, and decomposes at shallow temperatures. This discovery led to intensive studies on modified resins. Kim et al. [7] developed automobile friction material containing aramid pulp, potassium titanate, barite, graphite, novolac phenolic resin, and modified novolac phenolic resin. Only tribological properties (wear and friction) investigation was conducted on the developed material. It was reported that friction material with $10 \%$ of aramid pulp fiber and modified resin provided a stable coefficient of friction and lesser wear rate; however, the resin used in this study have toxic element harmful to human health and the study only focus on tribological properties such as wear and friction [39]. Thus this study combined carbon/carbon ingredients such as carbon fiber, carbon nanotube, and graphite to fabricate friction material. The selection of additives was based on each constituent availability and inherent properties and their ability to form a catenation. However, several studies on the development and characterization of carbon/carbon material for tribological products focus on tribological and thermal properties.

Consequently, there is limited available literature where the mechanical and absorption properties of this material are investigated. Besides, there is no report on composite mechanical properties with a combination of additives used in this study. Additionally, the absorption rate of friction materials provided in several studies [7, 12, 18-21, 40] [41]. However, information on the effect of absorption rate on friction material function such as wear and friction is limited in the available literature. Therefore, this study presents the mechanical, absorption properties and the effect of oil uptake on the tribological properties of carbon-based brake pad material

\section{MATERIALS AND METHODS}

Epoxy resin (matrix) and catalyst supplied with trade names LR20 and LH218, respectively, are used as a binder. The carbon fiber is used as reinforcement to enhance mechanical strength, thermal stability, creep, and wear resistance of composite materials. Carbon nanotube (CNT) and graphite $(\mathrm{G})$ were added to serve as a multifunctional filler and internal lubricant. Carbon nanotube (CNT) has an actual density ranging from $1-2 \mathrm{~g} / \mathrm{cm} 3$. Both tube length and diameter are $<100 \mathrm{~nm}$ in size. The graphite nanopowder was from hydrophobic natural graphite with 1-2.3g/ cm3 density, <100nm in size, and it an Iron-black to steelgrey in color.

\section{Preparation of carbon-based brake friction material}

The carbon-based friction material was prepared in two stages, which are mixing and casting processes. In the first stage, CNTs and graphite nanoparticle particles were dispersed in the matrix. The catalyst was added to the matrix/ nanoparticle blend, and carbon fiber was incorporated after that. $100 \mathrm{~g}$ of epoxy resin was measured in a beaker using Kern (model D-72336) digital electronic scale. It was

Table 1: The formulation of carbon-based friction material

\begin{tabular}{ccccccc} 
Additives & CBP 1 & CBP 2 & CBP 3 & CBP 4 & CBP 5 & CBP 6 \\
\hline Epoxy resin & 100 & 100 & 100 & 100 & 100 & 100 \\
\hline Carbon Fiber & 5 & 5 & 5 & 15 & 15 & 15 \\
\hline Carbon nanotube & 0.1 & 0.2 & 0.3 & 0.1 & 0.2 & 0.3 \\
\hline Graphite & 1 & 1 & 1 & 1 & 1 & 1
\end{tabular}


later placed on a hotplate and heated to $65^{\circ} \mathrm{C}$ to enable nanoparticle dispersion and reduce matrix viscosity afterward, small additives ranging from 1-5 wt. \% (Carbon nanotube of $0.1-0.3 \mathrm{wt}$. \% and $1 \mathrm{wt}$. \% of graphite powder) was incorporated into the resin slowly. Nanoparticles were blend using a mechanical stirrer at $500 \mathrm{rpm}$ for one hour to ensure uniform and homogeneous dispersion nanoparticles. The mixture was taken off the stirrer and allowed to cool down naturally to ambient temperature. The hardener was then added to the epoxy resin using a mixed ratio of $30 \mathrm{wt} . \%$ to the adhesive. Then, chopped carbon fiber (5wt. $\%$ and $15 \mathrm{wt}$. \%) was added to the different formulation, as shown in Table 1. Afterward, the mix was poured into an open plate mold. A composite sheet specimen of $12 \mathrm{~mm}$ was prepared by this casting method. Before pouring into the mold, the wax was applied on the inner surface of the plastic mold to facilitate easy composite removal after two days. The composite panel was removed and tested after two weeks of curing to ensure proper curing.

\section{Mechanical Testing}

Mechanical tests such as compression, shear, and hardness were carried out on wholly cured composite panel samples after fifteen days of casting. The purpose of investigating the mechanical properties was to determine the strength and stiffness of CBP. The carbon-based brake and ceramic brake pad materials were determined according to ASTM D 695 test standard. This test was carried out on samples using a Lloyd universal testing machine (Model 43) fitted with a $30 \mathrm{kN}$ load cell. Five samples were tested at ambient temperature, and the constant cross-head speed of the tests was $1.3 \mathrm{~mm} / \mathrm{min}$. The mean value of the five samples was reported in the numerical results section.

Barcol impresser hardness tester (model GYZJ-934-1) was used to determine the hardness property of the composite panel samples. Hardness properties of carbon-based brake and commercial friction materials were conducted to investigate the friction material's resistance to indentation. This investigation was performed according to the ASTM D 2583 test standard. A standard impresser with a steel truncated cone $(6.82 \mathrm{~mm}$ height and a tip diameter of $0.55 \mathrm{~mm}$ ) was used at room temperature. The intender was positioned on the surface of the composite panel, and a uniform downward pressure was applied by hand to collect direct readings on a dial indicator. Fifteen indentation readings were randomly collected on the sample, and the means value is reported.

Shear properties of friction material samples were investigated as per the ASTM D 732- 02 standard test specification. This investigation was done to determine the shear resistance. The test was conducted on the Lloyd universal testing machine (Model 43) filled with a $30 \mathrm{kN}$ load cell with shear tools. The shear tool of punch type was inhouse fabricated based on ASTM D 732-02. The friction material sample was rigidly clamped to the stationary and movable block (shear tool )to deflect during the test. A rectangular sample of $12.7 \times 12.7 \times 50 \mathrm{~mm}$ in width, thickness, and length by dimension used for this study was cut from both developed and commercial friction material using a cutting machine. The test sample had a parallel upper and lower surface. A hole of $11 \mathrm{~mm}$ diameter was drilled through the center of the sample. This hole was made using a pillar drilling machine.

The specimen was positioned over the punch pin and fixed firmly to it using bolt and nut. Subsequently, the tool jig was assembled, and the bolts were tightened to put the pin in place. The jig was positioned on the Lloyd universal testing machine and fastened. Each specimen was stressed until it fails. Five samples were investigated under room temperature at a speed of testing $1.3 \pm 0.3 \mathrm{~mm}(0.050 \pm 0.010$ in.)/min. The average values of five specimens were used for graphical illustrations and discussion

\section{Absorption rate}

The absorption for advanced and commercial brake pad material was investigated to determine the sample rate of water absorption and the effects of exposure to water or humid condition. Similarly, oil absorption of the rate of CBP and ceramic friction materials were investigated to determine the oil absorption rate and the effects of exposure to oil. These investigations were conducted on five samples as per ASTM D570-98 standard test specifications. The absorption rate was determined by immersing friction materials samples into the water at room temperature for 24hours. Before water immersion, the initial weight (g) of the CBP samples $F_{1}$ was taken on a Kern digital electronic scale accuracy (model D-72336). Subsequently, the sample was removed from the water, wiped with a piece of dry fabric, and weighed to measure the final weight $F_{2}$. The water absorption rate (\%) was calculated using the following equation, where $\boldsymbol{P}_{c}$ is the \% of absorption [42]:

$$
P_{c}=\frac{F_{2}-F_{1}}{F_{2}} \times 100
$$

Five specimens were tested, and the average value of the five samples was illustrated against the brake pad formulations.

\section{Abrasion test}

The tribological properties investigation of commercial and carbon-based friction material before and after soaked in oil was performed on a pin-on-disc apparatus. Tribometer was precisely calibrated for friction and wear measurements. Tribometer was also confirmed for the stability of the contact point and parasitic friction. A steel metal disc (diameter $350 \mathrm{~mm}$ and hardness $420 \mathrm{HV}$ ) was used as a counterpart. The wear test was carried out on a wear track of $250 \mathrm{~mm}$ diameter at a different sliding distance of (261.3 $\mathrm{m}, 650.4 \mathrm{~m}$, and $1300.3 \mathrm{~m}$ ) and fixed applied load of $10 \mathrm{~N}$. The resultant pressure and sliding speed were $138 \mathrm{~N} / \mathrm{m}^{2}$ and $0.7 \mathrm{~m} / \mathrm{s}$, respectively. The wear loss was measured as a mass loss of the composite samples using a highly accurate digital weighing scale (Kern, Germany, $0.01 \mathrm{~mm}$ accu- 


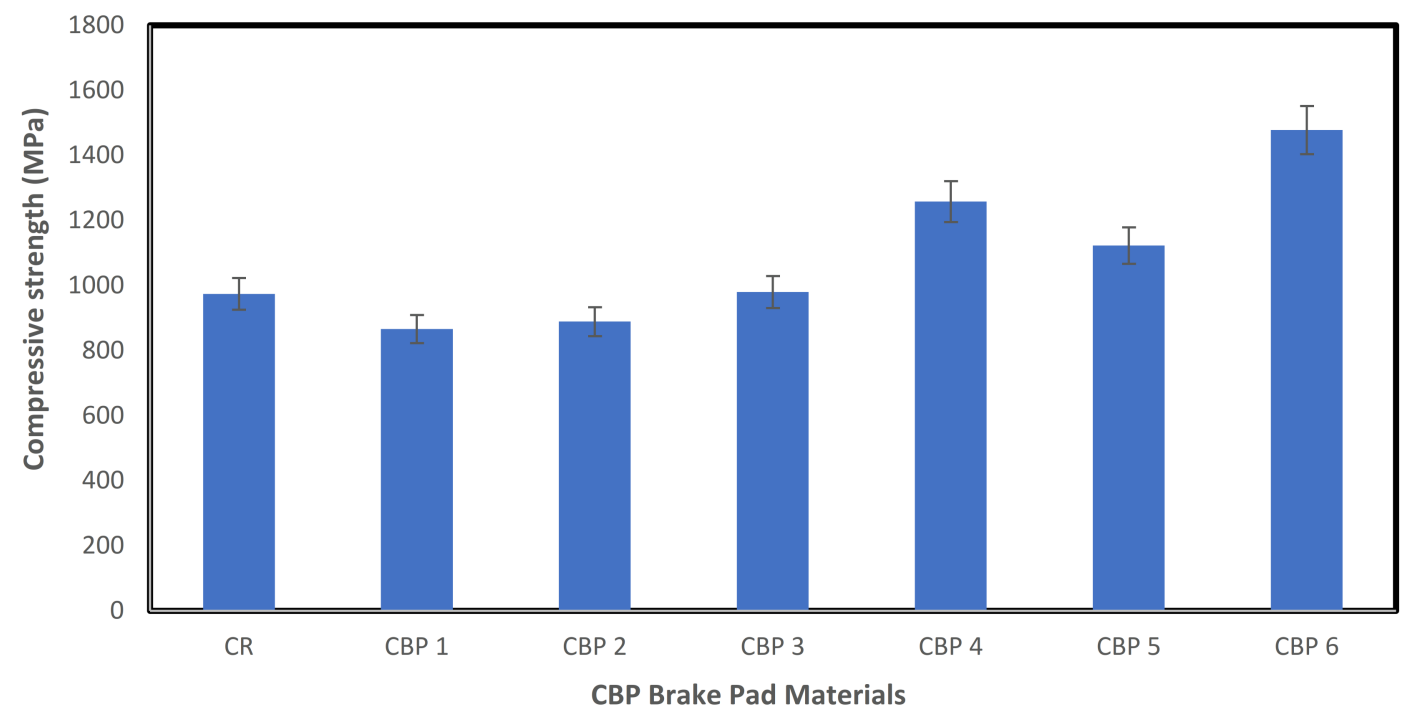

Figure 1: Compressive strength of carbon-based and commercial friction materials.

racy). Three samples were tested, and an average of three samples was reported. The specific wear rate and coefficient of friction were then calculated using equations 1 and 2 , respectively.

Where:

$$
\begin{gathered}
\mathbf{k}=\frac{\Delta \mathbf{V}}{\mathbf{N} \cdot \mathbf{x}} \\
\boldsymbol{\mu}=\frac{\mathrm{M}}{\mathrm{r} \cdot \mathbf{N}}
\end{gathered}
$$

$\mathrm{k}=$ specific wear rate,

$\mathrm{V}=$ the volume change (in $\mathrm{m} 3$ ),

$\mathrm{x}=$ total sliding distance (in $\mathrm{m}$ ),

$\mu=$ coefficient of friction,

$\mathrm{M}=$ torque induced in the specimen due to friction (in $\mathrm{N}$ $\mathrm{mm})$;

$\mathrm{r}=$ radius of the disc $(\mathrm{mm})$ and

$\mathrm{N}=$ normal load acting on the specimen (in $\mathrm{N}$ ) [23, 43].

\section{RESULT AND DISCUSSION}

\section{Compressive strength and modulus of friction material}

Figure 1 presents the compressive strength of developed and commercial friction materials. It was observed that the compressive strength for carbon-based friction materials varies with different formulations. The relationship between the quantity and nature of constituent influences the strength of the composite and hence determines final properties [4]. The varying compressive strength observed in Figure 1 may be attributed to the different concentrations of components in the formulation of each friction material. The carbon-based friction materials CBP 4 CBP 6 offered superior compressive strength compared to commercial friction materials.

On the contrary, carbon-based friction materials CBP 1 CBP 3 offered lower but statistically comparable CBP 1 CBP 3 with ceramic brake pad materials. The statistical comparativeness of CBP 1 - CBP 3 with low percentage loading of carbon fiber evidence that the selected carbonbased constituents possess excellent mechanical properties. This performance can be directly ascribed to carbon fiber loading as CBP reinforced with high carbon fiber loading exhibited greater strength. Furthermore, improvement in strength observed for CBP 4 - CBP 6 may be ascribed to the high loading of carbon fiber and the interconnecting (carbon-carbon) C-C bond of the CNTs and G showed in Figure 2. This interconnection bond accommodates the transfer of atom and electron of these carbon-based materials, formed a covalent bonding that enhanced the relationship between carbon fiber and the epoxy matrix, later resulted in an improvement.

Similarly, the improved force resistance and loadcarrying capability of carbon fibers may be the reason for the increased strength. Although, loading of $0.1 \mathrm{wt}$. \% and 3 wt. \% CNTs have a significant effect on the strength of CBPs, however friction material with $0.3 \mathrm{wt}$. \%CNTs offered superior strength. This performance is consistent with literature where loading of $0.3 \mathrm{wt}$. \% CNTs and the loading of $1 \%$ G.N. improved mechanical properties[23, 4547]. The compressive strength of $15 \%$ carbon fiber-filled CBP friction materials enhanced with a corresponding increase in carbon nanotube content, and CBP 6 had a compressive force that was about $51 \%$ higher than that of C.R. friction material. This implied that CBP 6 exhibited better resistance to compressive stress than other CBPs and commercial brake pads. Correspondingly, the better force resistance and load carrying competence of carbon fibers may be another reason for the increased strength.

Figure 2 shows the compressive modulus for the developed and commercial brake pad material. It was observed that $\mathrm{CBP} 1, \mathrm{CBP} 3, \mathrm{CBP} 4, \mathrm{CBP} 5$, and CBP 6 brake pad material exhibited improved stiffness properties compared to commercial brake pad material, with CBP 4 having about $35 \%$ modulus more significant than that of commercial 


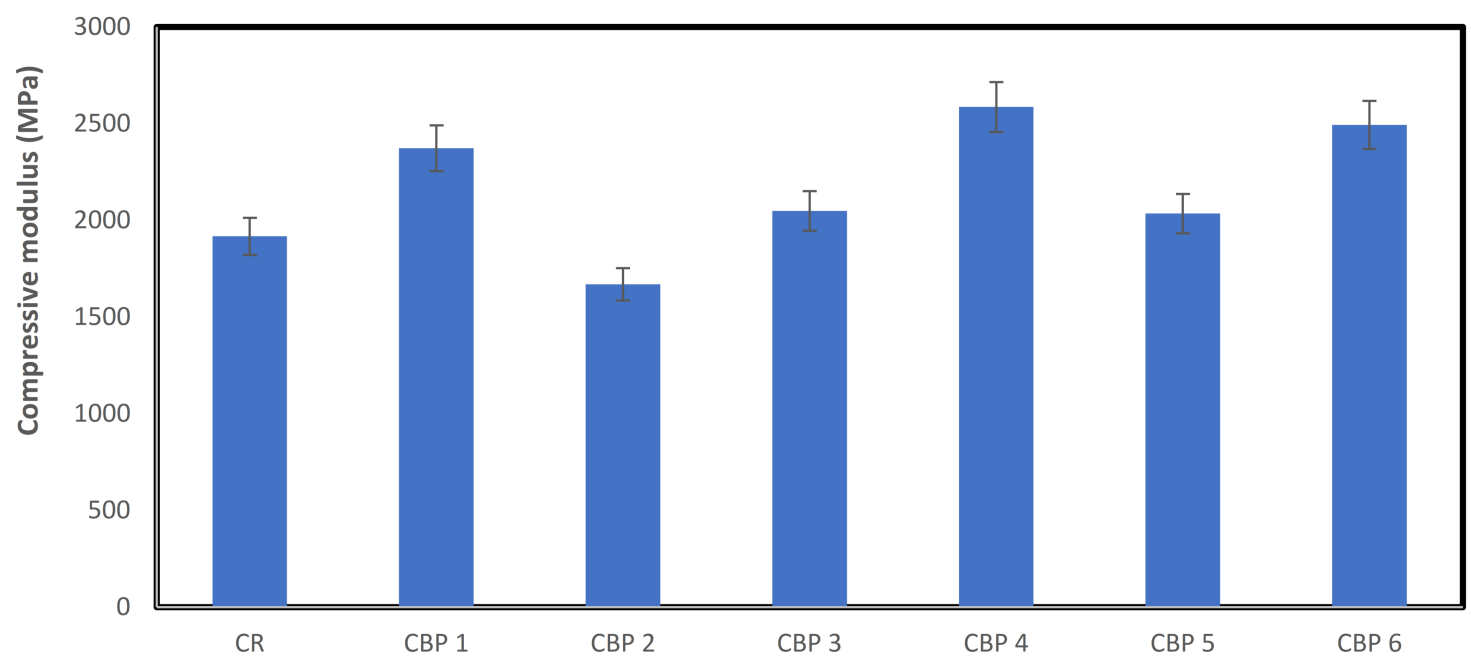

CBP Brake Pad Materials

Figure 2: Compressive stiffness of carbon-based and commercial friction materials.

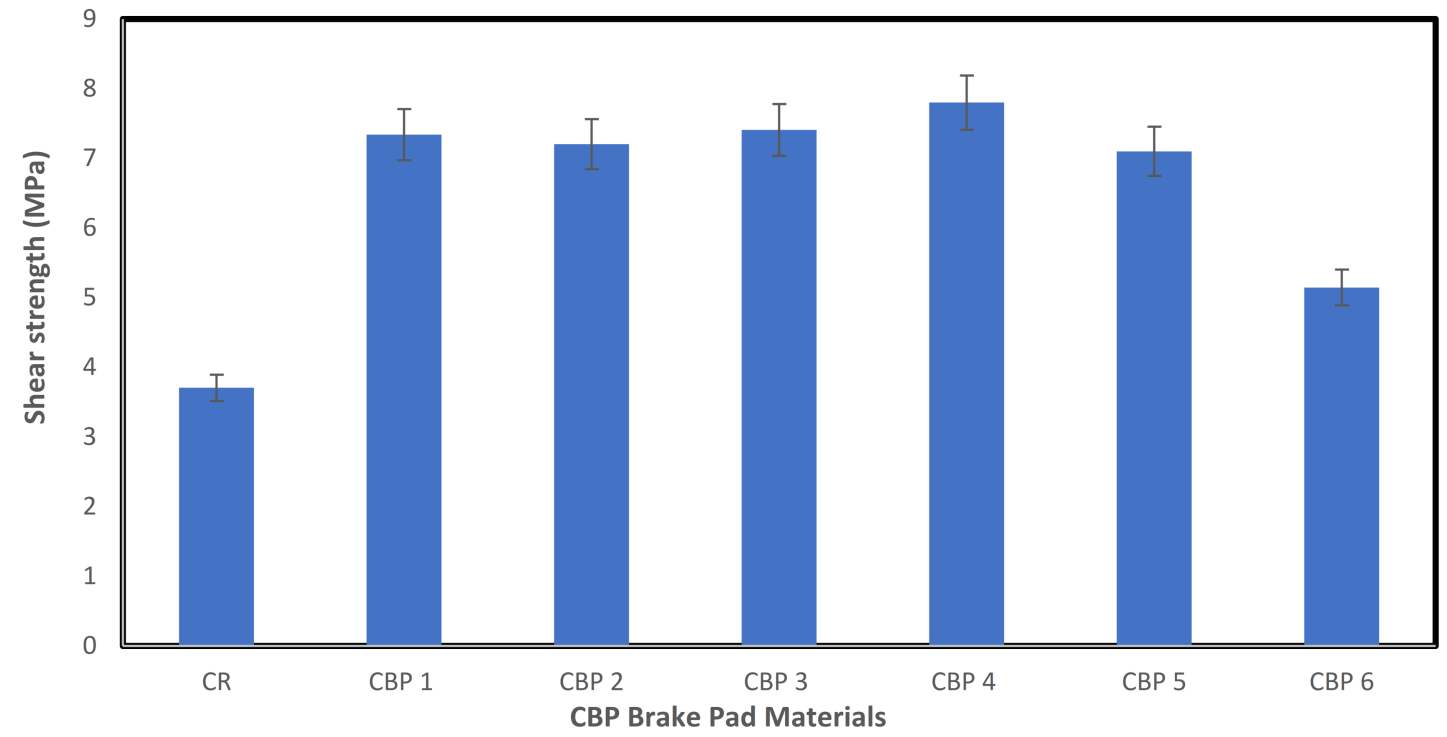

Figure 3: Shear strength of carbon-based and commercial friction materials.

brake pad material. These improved properties suggested that the interconnecting (carbon-carbon) $\mathrm{C}-\mathrm{C}$ bonding is responsible for improving strength and enhancing the stiffness of the CBP friction material. Given the brake pad material stiffness relationship, the higher stiffness of CBP friction material indicates a better resistance to abrasion that may be translated excellent tribological properties.

\section{Shear strength}

Shear strength values for the developed and commercial friction material were measured using a shear tool. Five specimens were tested; the mean value of the five specimens is illustrated in figure 3. It was observed that all carbon-based friction materials exhibited higher shear strength than that of the commercial friction material (3.706 $\mathrm{MPa})$. Although the CBP friction materials have improved shear strength than commercial friction material, both types of brake pad material appear to have superior shear strength compared to the standard shear strength $(2.10$ $\mathrm{MPa})$. The RS 124 specification (materials specification) for brake pad material at ambient temperature. Moreover, CBP 4 exhibited a higher shear strength of 7.800 MPa. This enhancement is over $100 \%$ greater compared to the commercial friction material.

It is noteworthy that all the carbon-based friction materials exhibited higher shear strength. This improved strength is indicated that the combination of carbon-based additive used to provide a composite material showed good interfacial bonding, resulting in strength improvement $[8,29]$.

It is noteworthy that all the carbon-based brake pad materials exhibited higher shear strength. This shear re- 

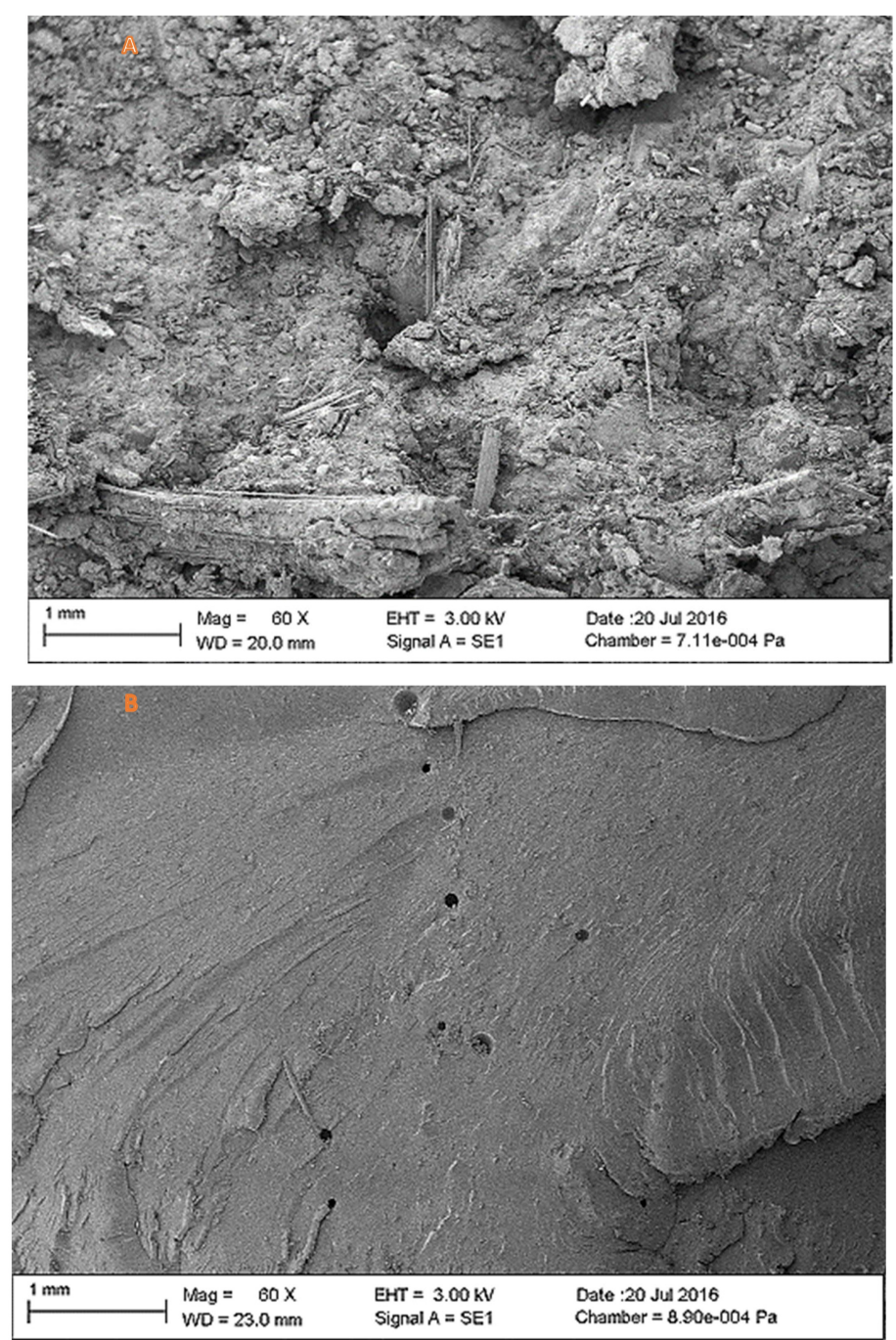

Figure 4: SEM micrograph showing shear fracture surface of (A) commercial brake pad material and (B) carbon-based brake pad material

sistance indicated that the combination of carbon-based additive used to provide a composite material with good interfacial bonding, resulting in strength improvement $[8$, $29,48]$.

The fracture mechanism investigation was conducted by observing the fracture surfaces of brake pad materials under a Scanning Electron Microscope (SEM). This study was undertaken to determine the fracture mechanism and failure mode of the brake pad material. The shear portions of the developed brake pad material were cemented together after the testing machine has detected the failure and stopped. Nevertheless, cracks were observed on the stressed side. After that, cracked surfaces were detached for shear fracture analysis to determine the shear mechanism for both brake pad materials. A limited amount of fibers bonded together at one end was observed on the micrograph of commercial brake pad material. This micrograph suggests an inhomogeneous dispersion of fibers in the matric and filler constituents. Besides, the combination of additives incorporated to produce commercial brake pad material seems not uniformly mixed, as fibers are separated for the matrix/filler additives. This poor connectivity of the components consequently caused fatigue fracture and degradation observed on the shear surface of commercial friction material shown in figure 4 a.

On the other hand, a relatively smooth and tight surface was observed on the shear fracture surface of the developed brake pad. It is challenging to identify the components of the CBP brake pad material shown in figure $4 \mathrm{~b}$. This structure revealed a homogeneous dispersion of carbon-based additives. This uniform dispersion improved additives bonding that consequently formed a more hardened feature shown in Figure $4 \mathrm{~b}$. Therefore, this structure created a better load carrying mechanism, which reduced additives disintegration and enhanced shear strength. The close packing and more stringent structure may be the reason for low absorption properties and improved compressive strength.

This fatigue rupture can be attributed to the high loading of silicon carbide, which protrudes creak that eventually affects the shear strength negatively.

\section{Hardness property}

Figure 5 presents the variation of hardness values for carbon-based and commercial friction materials. It was observed that the hardness stated was separate for each formulation. An insignificant difference in hardness values was observed for friction materials (CBP 1- CBP 3) with 5 $w t \%$ of carbon fiber. The same trend was observed for CBP 4- CBP 6 friction materials with $15 \mathrm{wt} \%$ loadings of carbon fiber; however, these friction materials exhibited a higher hardness value than CBP 1- CBP 3. This higher hardness property implies that the percentage loading of carbon fiber has a dominating effect on modifying the hardness properties of composite material. This conclusion corresponds with literature where carbon fiber loading improves mechanical properties such as hardness properties $[49,50]$.

Furthermore, insignificant differences in hardness values of friction materials with the same carbon loading suggest consistent processing of the $\mathrm{CBP}$, which determines the hardness of these friction materials. This trend corresponds to available literature where formulation and processing consistency determines hardness [8, 35]. It was observed that ceramic brake pad material exhibited a high hardness property of $37.3 \mathrm{HB}$ than CBP brake pad materials. This hardness property depicts that commercial brake pad material has better surface hardness than CBP brake pad materials. This hardness performance can be attributed to the loading and homogenous dispersion of ceramic additives such as silicon carbide in the brake pad material. This hardness property exhibited by commercial brake pad material suggests a brittle material, which resulted in a compressive modulus reported in Figure 2.

\section{Barrier properties}

Figure 6 showed that the absorption rate for carbon- 


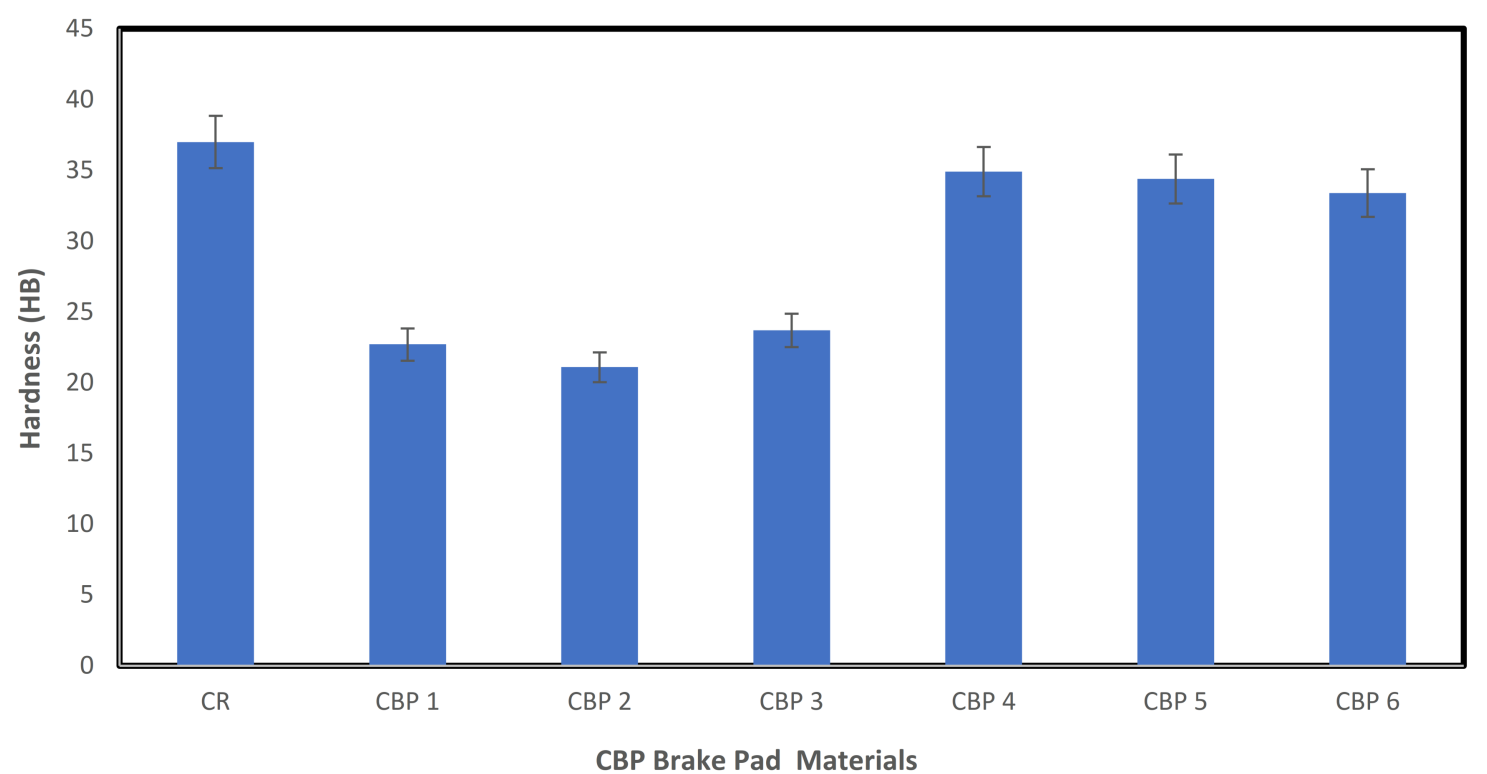

Figure 5: Hardness properties of carbon-based and commercial friction materials.

based and commercial brake pad material. It was observed that friction materials offered small oil absorption properties fluctuating between 1.012 and 0.46 , significantly lower than $0.5 \%$ obtained for commercial brake pad.

This trend is lesser compared to $2.34 \%$ reported by Mayowa et al. and well compared with $0.44 \%$ reported by Dagwa et al. [51, 52]. It was further observed that all the carbon-based friction materials exhibited a lesser oil absorption rate than commercial friction material. Significantly, CBP 3 offered the lowest absorption rate of 0.12 , which was $76 \%$ better than $0.5 \%$ obtained from commercial friction material.

This noteworthy reduction in the absorption rate can be related to the hydrophobic nature of the carbon-carbon component [53] and the interconnecting bond formed by the additives. Closer packing of the carbon-carbon additives may be another reason for the low sorption, which resulted in a more stringent relationship, which barely allows water penetration [51]. The higher rate of oil in the commercial may result from poor compatibility of friction constituent and porosity.

\section{Tribological properties}

The tribological property, which is wear and friction of the commercial and carbon-based friction material, is shown in table 2. It presents the wear rate, and the coefficient of friction of commercial and carbon-based friction material before and after soaked in oil was measured as a function of sliding distances. It was observed that the wear rate of commercial and carbon-based friction material reduces as sliding distance increases. The wear debris glued on the counterpart shown in Figure 7e during the sliding abrasion process may be attributed to a reduced wear rate. Similarly, this abrasion performance may probably be due to the toughness and better thermal resistance of additives incorporated in C.R. This trend is consistent with available literature where friction material exhibited a reduced wear rate with a corresponding increase in sliding distances [23, 43]. It was also observed that the carbon-based friction material exhibited a lesser wear rate than commercial friction materials. This output may be attributed to the homogenous dispersion of carbon fiber and the nanoparticle potential, resulted in effective wear resistance.

It can be seen that the oil absorption rate of the friction material harms the wear rate. Figure 6 shows that C.R. absorbed a high oil content, and table 2 shows that this material has the highest wear rate. This performance may be attributed to weakness caused by oil content to the bonding existing between the additive in the material, which eventually led to a higher wear rate. Although the carbonbased friction affected was by oil uptakes; however, it has a more negligible effect on their wear rate irrespective of sliding distance. However, a decrease in wear rate with a corresponding increase in sliding distance was observed for CBP. At $261.8 \mathrm{~m}$ sliding distance, it was observed that oil absorption has minimal effect on the wear rate of CBP3 and CBP4 compared to other CBP formulations. This wear resistance may be related to the low oil absorption of both frictional samples shown in Figure 6. Table 2 also presents that CBP 2, with oil absorption slightly higher than CBP3 and CBP3, exhibited a greater wear rate at $261.8 \mathrm{~m}$ sliding distance. This trend corresponds with compressive strength and hardness properties shown in Figures 2 and 5. This output implies that CBP 2 may have good solvent absorption resistance but have a structure that has less staminal that can not withstand an external force, such as compressive stress and asperities stress generated at the counterpart. For C.R., CBP1, CBP5, CBP6, an increase in wear rate was observed at $261.8 \mathrm{~m}$ sliding distance. This output may be attributed to high oil absorption.

Further reduction in wear rate was at $650.4 \mathrm{~m}$, and $1300.8 \mathrm{~m}$ sliding distance was observed for the friction ma- 


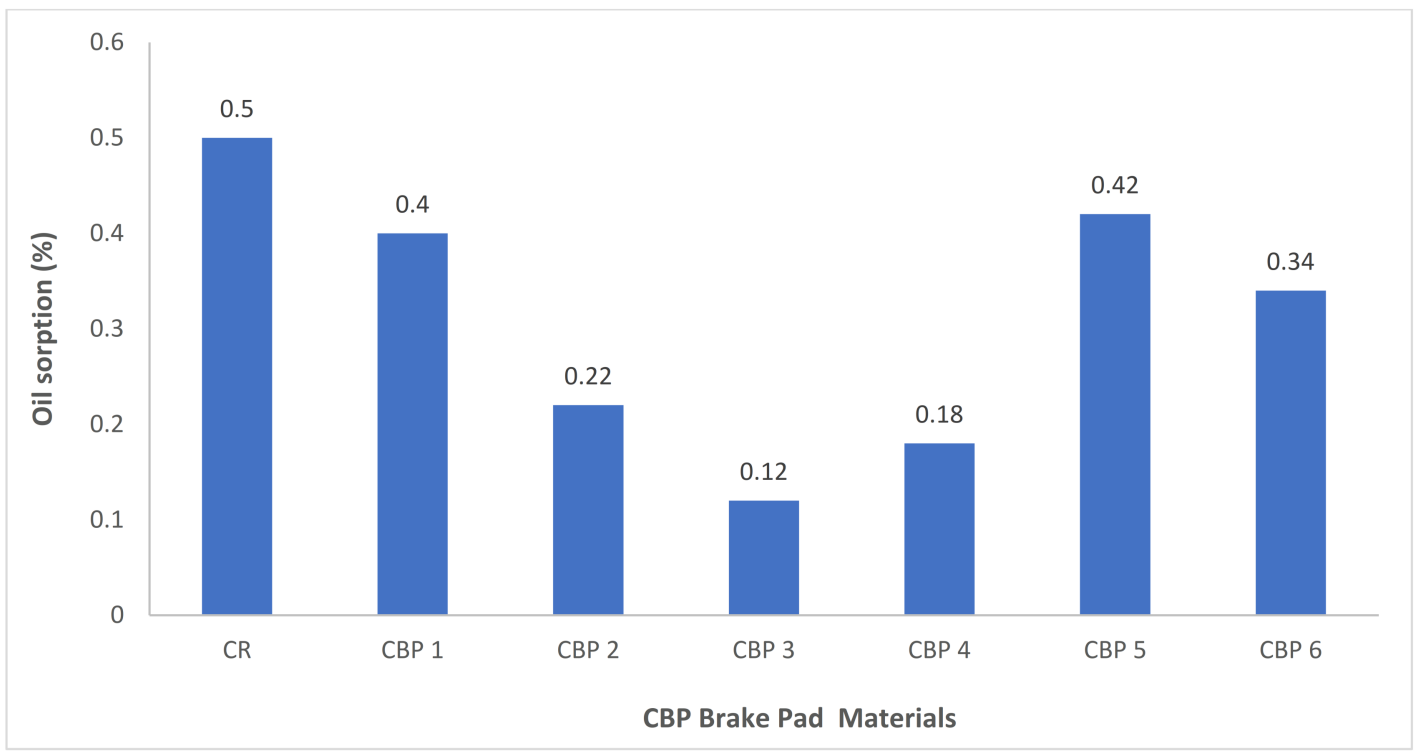

Figure 6: Histogram showing the oil absorption rate of carbon-based and commercial friction materials.

terials. The improvement in wear resistance may be an accumulation of worn debris forming barriers between the counterpart and friction material to contact directly, leading to a reduced wear rate. Also, it is convinced friction material produces wear debris, having the material and oil content creating a layer on the counterpart surface. The oil content may have resulted in free slipping between the counterpart and the friction material, resulting in reduced wear rate and friction coefficient shown in Table 2.

A sharp drop in wear rate was observed $650.4 \mathrm{~m}$ and $1300.8 \mathrm{~m}$ for CBP, especially for CBP6. The wear rate CBP6 exhibited at $650.4 \mathrm{~m}$ sliding distance was about $90 \%$ lower than the wear rate observed at $261.8 \mathrm{~m}$ sliding distance. This performance proved may be attributed to the interconnecting bond formed by the carbon-carbon component. Furthermore, the wear rate exhibited by CBP may be attributed to the good thermal properties of incorporated and synergistic functions of SCF, G.N., and MWCNTs, acting in concert to produce a coiled and more stabled structure resulting in high strength, stiffness, improved oil absorption resistance, and tougher.

For the coefficient of friction (CoF), C.R. exhibited higher CoF than the CBP before soaked in oil. This frictional output may be attributed to tougher abrasive materials embedded in the material, and transferring of this tougher particle on the counterpart surface inform of wear debris increases CoF. A stable CoF observed for CBP friction materials may be attributed to graphite function serving as an internal lubricant. As expected, a reduction in $\mathrm{CoF}$ was observed after friction materials were drenched in oil. C.R. with a higher oil content offered a significant reduction in CoF after socked in oil for 24 hours. The lubrication nature of oil may be attributed to the reduction of $\mathrm{CoF}$ of commercial friction material subsequently socked in oil. The CoF of CBP 4 and CBP 6 were less affected by the oil content in the friction material system. This performance may be linked with the less oil absorption of CBP showed in Figure 6.

\section{Worm Mechanisms}

Figure 7 shows the SEM micrographs of friction material worn surfaces magnified at 500X to determine the braking performance mechanism of the brake pads. Rough debris formed plateaus, broken fiber, and inconsistent surface textures were observed on the worn surface $6 a$ of the commercial brake pad before soaked in oil. The plateaus formed may be due to the high content of tougher additives and broken fibers, which control abrasion and increase the friction coefficient. The hard inclusion and broken fibers became more visible on the C.R. worn surface after drenched in oil. A relatively smooth worn surface and dark spots were observed on worn surface $7 \mathrm{~b}$, which may be the lodges of oil absorbed by C.R., which eventually increase the wear rate and coefficient of friction shown in Table 2.

The worn surface of CBP before socked in oil 7c and CBP before socked in oil $7 \mathrm{~d}$ reveal a tougher surface texture, self-sustaining layer, consistent strand of fiber, and plateaus were observed. This robust structure was formed due to the synergistic effect between carbon-based additives within the binder. Homogeneous dispersion and good adhesion within the binder may be attributed to a lesser wear rate, and a steady coefficient of friction observed in Table 2. Figure $6 \mathrm{c}$ showing the worn surface of CBP before drenched in oil shows a tougher and darker surface texture compared to $6 c$ worn surface. The oil absorbed by CBP may be the reason for the change in surface texture, which caused a slight increase in wear rate and $\mathrm{COF}$ reduction. The counterpart surface micrograph shown in Figure 6e provided more information on the mechanism that governs the tribological properties observed in Table 
Table 2: The tribological properties of commercial and carbon-based friction material before and after soaked in oil.

\begin{tabular}{|c|c|c|c|c|c|c|}
\hline $\begin{array}{l}\text { Friction } \\
\text { materials }\end{array}$ & $\begin{array}{c}\text { Wear rate } \\
\text { before } \\
\text { socking in oil }\end{array}$ & $\begin{array}{l}\text { Wear rate after } \\
\text { socking in oil } \\
\text { for } 24 \mathrm{Hrs} .\end{array}$ & $\begin{array}{c}\text { Remarks } \\
(\%)\end{array}$ & $\begin{array}{l}\text { CoF before } \\
\text { socking in } \\
\text { the oil }\end{array}$ & $\begin{array}{l}\text { CoF after } \\
\text { socked in the } \\
\text { oil for } 24 \mathrm{Hrs} \text {. }\end{array}$ & $\begin{array}{c}\text { Remarks } \\
(\%)\end{array}$ \\
\hline & \multicolumn{2}{|c|}{ @ 261,8m (sliding distance) } & \multicolumn{4}{|c|}{ @ 261,8m (sliding distance) } \\
\hline CR & $1,07243 \times 10^{-05}$ & $2,19 \times 10^{-05}$ & 104 & 0,5225 & 0,45 & 13.9 \\
\hline CBP 1 & $1,47142 \times 10^{-05}$ & $7,14951 \times 10^{-06}$ & 50 & 0,504248 & 0,482222 & 4.3 \\
\hline CBP 2 & $4,12827 \times 10^{-06}$ & $1,11715 \times 10^{-05}$ & 63 & 0,484641 & 0,450776 & 7.0 \\
\hline CBP 3 & $9,57112 \times 10^{-06}$ & $1,52248 \times 10^{-05}$ & 37 & 0,484815 & 0,455947 & 5.9 \\
\hline CBP 4 & $8,84079 \times 10^{-06}$ & $1,19159 \times 10^{-05}$ & 34 & 0,504248 & 0,482026 & 4.3 \\
\hline CBP 5 & $1,16852 \times 10^{-05}$ & $1,81428 \times 10^{-05}$ & 55 & 0,494804 & 0,455947 & 7.8 \\
\hline \multirow[t]{2}{*}{ CBP 6} & $4,61259 \times 10^{-06}$ & $8,84079 \times 10^{-06}$ & 92 & 0,526471 & 0,519241 & 1.3 \\
\hline & \multicolumn{2}{|c|}{ @ 650.4m (sliding distance) } & \multicolumn{4}{|c|}{ @ 650.4m (sliding distance) } \\
\hline CR & $9,64 \times 10^{-06}$ & $1,78 \times 10^{-05}$ & 85 & 0,50963 & 0,53625 & 5.3 \\
\hline CBP 1 & $5,6528 \times 10^{-06}$ & $7,0151 \times 10^{-06}$ & 24 & 0,483333 & 0,460294 & 4.8 \\
\hline CBP 2 & $4,84079 \times 10^{-06}$ & $6,2715 \times 10^{-06}$ & 29 & 0,484641 & 0,446017 & 7.8 \\
\hline CBP 3 & $6,92546 \times 10^{-06}$ & $8,32228 \times 10^{-06}$ & 20 & 0,497582 & 0,47125 & 5.2 \\
\hline CBP 4 & $9,76634 \times 10^{-06}$ & $8,91767 \times 10^{-06}$ & 8.6 & 0,48225 & 0,461026 & 4.39 \\
\hline CBP 5 & $9,84019 \times 10^{-06}$ & $7,600 \times 10^{-06}$ & 22.7 & 0,483085 & 0,45235 & 6.3 \\
\hline \multirow[t]{2}{*}{ CBP 6} & $1,54137 \times 10^{-06}$ & $1,37096 \times 10^{-06}$ & 11.1 & 0,504248 & 0,49375 & 2.1 \\
\hline & \multicolumn{2}{|c|}{ @ 1300,8m (sliding distance) } & \multicolumn{4}{|c|}{ @ 1300,8m (sliding distance) } \\
\hline CR & $7,70687 \times 10^{-06}$ & $1,39 \times 10^{-05}$ & 80.3 & 0,484947 & 0,455815 & 6.0 \\
\hline CBP 1 & $2,78677 \times 10^{-06}$ & $3,1138 \times 10^{-06}$ & 11.7 & 0,491258 & 0,465248 & 5.2 \\
\hline CBP 2 & $6,7203 \times 10^{-06}$ & $8,0656 \times 10^{-06}$ & 20 & 0,49447 & 0,45544 & 7.96 \\
\hline CBP 3 & $7,2228 \times 10^{-06}$ & $8,53329 \times 10^{-06}$ & 18.2 & 0,485815 & 0,455947 & 6.1 \\
\hline CBP 4 & $8,73829 \times 10^{-06}$ & $9,22518 \times 10^{-06}$ & 5.3 & 0,47248 & 0,448337 & 5.0 \\
\hline CBP 5 & $6,45402 \times 10^{-06}$ & $7,81077 \times 10^{-06}$ & 20.8 & 0,497582 & 0,455947 & 8.5 \\
\hline CBP 6 & $7,6717 \times 10^{-06}$ & $8,26392 \times 10^{-06}$ & 7.7 & 0,500915 & 0,489947 & 2.3 \\
\hline
\end{tabular}

2. Wear track showing glued debris texture, loose debris, and counterpart asperities observed on this counterpart micrograph are the wear and friction mechanisms. It was observed that debris covered the counterpart's asperities, reducing the direct contact of samples and counterpart asperities, leading to a decrease in wear rate and CoF. It is well known that an increase in sliding distance increases the period at that samples and counterpart asperities remain in contact. However, a build-up of debris generated during the time samples and counterpart in fixed contact, as shown in Figure 7e, blogs into the asperities, reducing wear and control $\mathrm{CoF}$. 

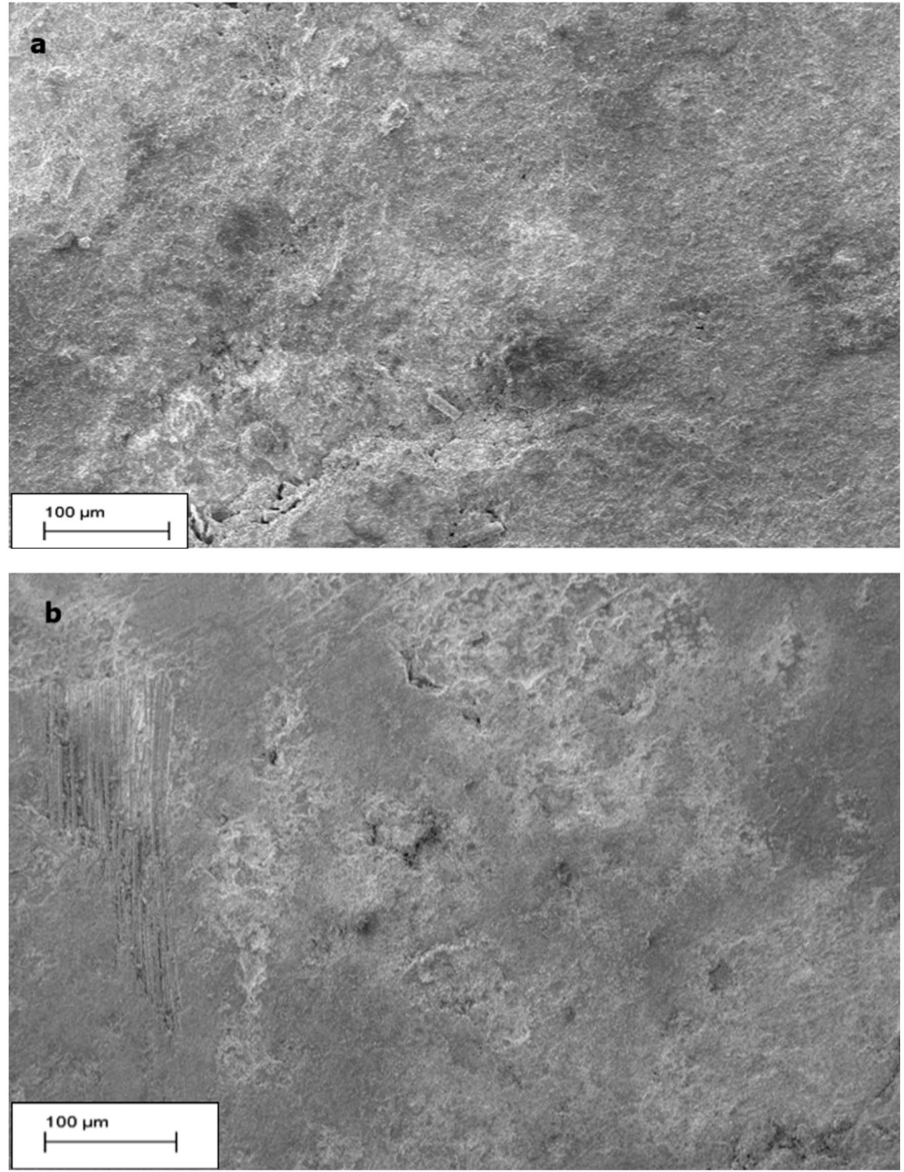

Figure 7: SEM micrographs showing worn surfaces of; (a) C.R. before socked in oil (b) C.R. after socked in oil (c) CBP before

\section{CONCLUSION}

The mechanical strength and absorption properties of carbon-based and ceramic brake pad materials were successfully determined and compared. Carbon-based brake pad materials offered compressive strength and modulus, shear strength, comparative statistical hardness, and lower water intake and oil absorption rate than that of ceramic brake pad material. This performance was attributed to the loading of carbon fiber and the interlocking (carboncarbon) C-C bond of the CNTs and G. The loading of carbon-based filler often forms covalent bond structures by exchanging or transferring of atom and electron, which enhance interlocking and facial adhesion of composite components. This structure in turn improved the mechanical, oil barrier and tribological properties of carbon-based brake pad materials. This structure eventually resulted in improved strength and reduced solvent absorption behaviours. This research suggests that carbon-based friction material (CBP) can be used as an alternative material for tribological products application based on the improved mechanical and absorption properties observed. The compactness, improved stiffness, shear strength, and hardness properties of carbon-based brake pad material favorable for the development of different tribological products.
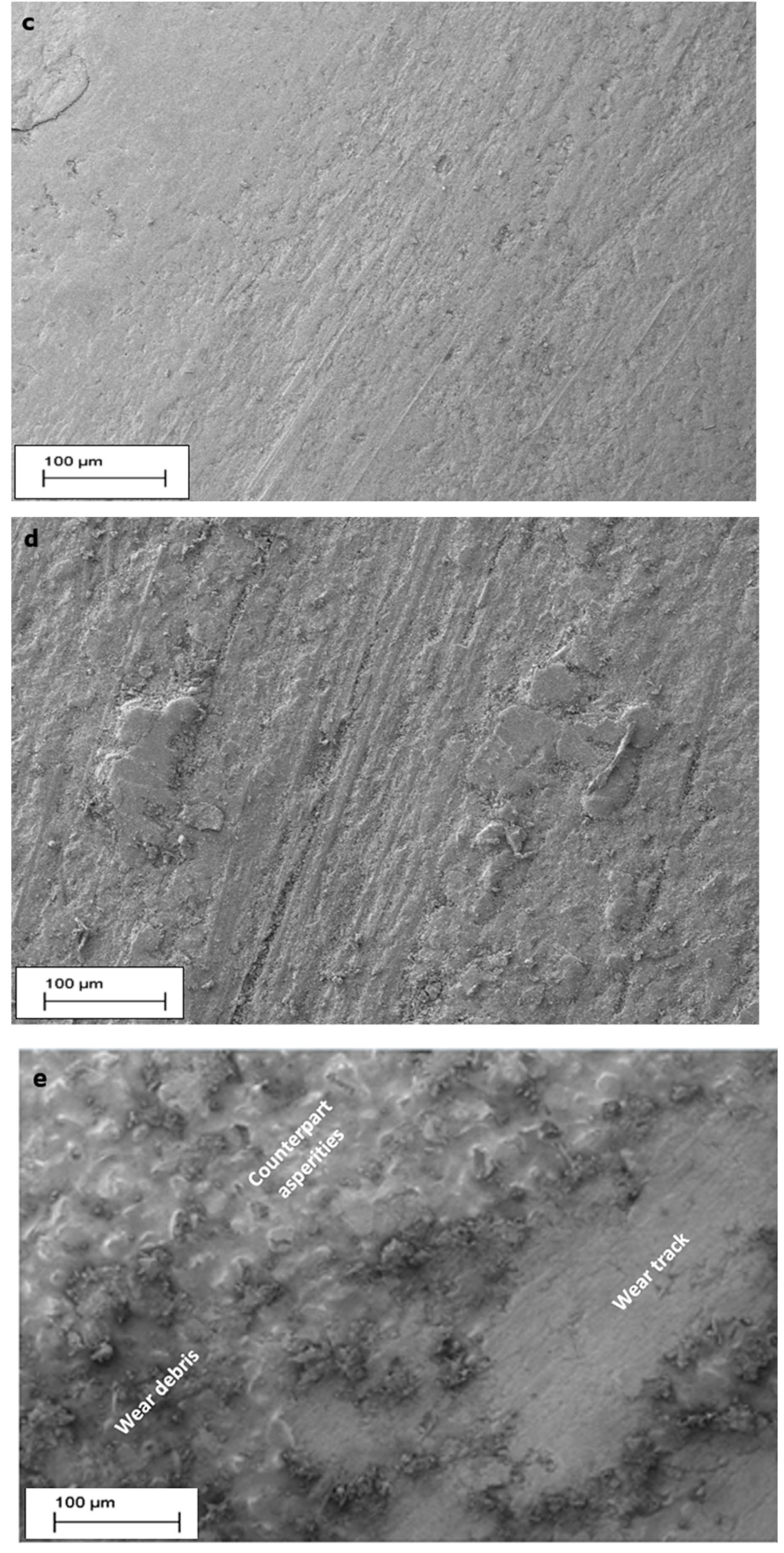

\section{Conflict of Interest Statement}

The authors declare that they have no conflict of interest as all author is affiliated to the institution as academic staff and students.

\section{Reference}

[1] X. Quan, J. Mo, B. Huang, B. Tang, H. Ouyang, and Z.R. Zhou, "Influence of the Friction Block Shape and Installation Angle of High-speed Train Brakes on Brake Noise," Journal of Tribology, pp. 1-18, 2019. https://doi.org/10.1115/1.4045262

[2] M. Boz and A. Kurt, "The effect of $\mathrm{Al} 2 \mathrm{O} 3$ on the friction performance of automotive brake friction mate- 
rials," Tribology International, vol. 40, no. 7, pp. 1161-1169, 2007/07/01/2007, doi: https:// doi.org/10.1016/j.triboint.2006.12.004.

[3] R. Yun, P. Filip, and Y. Lu, "Performance and evaluation of eco-friendly brake friction materials," Tribology International, vol. 43, no. 11, pp. 2010-2019, 2010/11/01/ 2010, doi: https:// doi.org/10.1016/ j.triboint.2010.05.001.

[4] M. U. Azam and M. A. Samad, "Tribological evaluation of a UHMWPE hybrid nanocomposite coating reinforced with nanoclay and carbon nanotubes under dry conditions," Journal of Tribology, vol. 140, no. 5, 2018. https://doi.org/10.1115/1.4039956

[5] K. Friedrich, Z. Zhang, and A. K. Schlarb, “Effects of various fillers on the sliding wear of polymer composites," Composites science and technology, vol. 65, no. 15-16, pp. 2329-2343, 2005. https:// doi.org/10.1016/j.compscitech.2005.05.028

[6] H. Jang, K. Ko, S. Kim, R. Basch, and J. Fash, “The effect of metal fibers on the friction performance of automotive brake friction materials," Wear, vol. 256, no. 3-4, pp. 406-414, 2004. https://doi.org/10.1016/ S0043-1648(03)00445-9

[7] S. J. Kim and H. Jang, "Friction and wear of friction materials containing two different phenolic resins reinforced with aramid pulp," Tribology international, vol. 33, no. 7, pp. 477-484, 2000. https:// doi.org/10.1016/S0301-679X(00)00087-6

[8] O. Gbadeyan, K. Kanny, and M. T.P, “Tribological, mechanical, and microstructural of multiwalled carbon nanotubes/short carbon fiber epoxy composites," Journal of Tribology, vol. 140, no. 2, 2018. https://doi.org/10.1115/1.4037357

[9] M. H. Cho, S. J. Kim, D. Kim, and H. Jang, "Effects of ingredients on tribological characteristics of a brake lining: an experimental case study," Wear, vol. 258, no. 11-12, pp. 1682-1687, 2005. https:// doi.org/10.1016/j.wear.2004.11.021

[10] K. Liew and U. Nirmal, "Frictional performance evaluation of newly designed brake pad materials," Materials \& Design, vol. 48, pp. 25-33, 2013. https:// doi.org/10.1016/j.matdes.2012.07.055

[11] U. Idris, V. Aigbodion, I. Abubakar, and C. Nwoye, "Eco-friendly asbestos free brake-pad: Using banana peels," Journal of King Saud University-Engineering Sciences, vol. 27, no. 2, pp. 185-192, 2015. https:// doi.org/10.1016/j.jksues.2013.06.006

[12] D. Yawas, S. Aku, and S. Amaren, "Morphology and properties of periwinkle shell asbestos-free brake pad," Journal of King Saud University-Engineering Sciences, vol. 28, no. 1, pp. 103-109, 2016. https:// doi.org/10.1016/j.jksues.2013.11.002

[13] Nidhi, B. Satapathy, J. Bijwe, and N. Majumdar,
"Influence of modified phenolic resins on the fade and recovery properties of the friction materials: Supportive evidence multiple criteria decisionmaking method (MCDM)," Journal of Reinforced Plastics and Composites, vol. 25, no. 13, pp. 1333 1340, 2006. https:// doi.org/10.1177/0731684406063527

[14] H. Hwang, S. Jung, K. Cho, Y. Kim, and H. Jang, "Tribological performance of brake friction materials containing carbon nanotubes," Wear, vol. 268, no. 34, pp. 519-525, 2010. https://doi.org/10.1016/ j.wear.2009.09.003

[15] E. F. EL-kashif, S. A. Esmail, O. A. Elkady, B. Azzam, and A. A. Khattab, "Influence of carbon nanotubes on the properties of friction composite materials," Journal of Composite Materials, p. 0021998319891772, 2019. https:// doi.org/10.1177/0021998319891772

[16] K. Rupiyawet, K. Kaewlob, P. Sujaridworakun, and W. Buggakupta, "Optimization of Mixing Conditions on the Physical and Tribological Properties of Brake Pads," in Key Engineering Materials, 2019, vol. 824: Trans Tech Publ, pp. 67-72. https:// doi.org/10.4028/www.scientific.net/KEM.824.67

[17] H. Jin et al., "Comparative tribological behavior of friction composites containing natural graphite and expanded graphite," Friction, pp. 1-11, 2019.

[18] P. J. Blau, "Compositions, Functions, and Testing of Friction Brake Materials and Their Additives; TOPICAL," Oak Ridge National Lab., 2001. https:// doi.org/10.2172/788356

[19] F. Kennedy, A. Balbahadur, and D. Lashmore, "The friction and wear of $\mathrm{Cu}$-based silicon carbide particulate metaal matrix composites for brake applications," Wear, vol. 203, pp. 715-721, 1997. https:// doi.org/10.1016/S0043-1648(96)07451-0

[20] K. Takahashi, M. Yoshida, Y. Hagiwara, K. Kondoh, Y. Takano, and Y. Yamashita, "Titanium and/or titanium alloy sintered friction material," ed: Google Patents, 1999.

[21] T. Peng, Q. Yan, G. Li, X. Zhang, Z. Wen, and X. Jin, "The braking behaviors of $\mathrm{Cu}$-based metallic brake pad for high-speed train under different initial braking speed," Tribology Letters, vol. 65, no. 4, p. 135, 2017. https:// doi.org/10.1007/s11249-017-0914-9

[22] O. J. Gbadeyan and K. Kanny, “Tribological Behaviors of Polymer-Based Hybrid Nanocomposite Brake Pad," Journal of Tribology, vol. 140, no. 3, p. 032003, 2018. https://doi.org/10.1115/1.4038679

[23] O. J. Gbadeyan, K. Kanny, and T. P. Mohan, "Influence of the multi-walled carbon nanotube and short carbon fibre composition on tribological properties of epoxy composites," Tribology - Materials, 
Surfaces \& Interfaces, vol. 11, no. 2, pp. 59-65, 2017/04/03 2017, doi: 10.1080/17515831.2017.1293763. https:// doi.org/10.1080/17515831.2017.1293763

[24] Z. Shen, S. Bateman, D. Y. Wu, P. McMahon, M. Dell'Olio, and J. Gotama, "The effects of carbon nanotubes on mechanical and thermal properties of woven glass fibre reinforced polyamide- 6 nanocomposites," Composites Science and Technology, vol. 69, no. 2, pp. 239-244, 2009. https:// doi.org/10.1016/i.compscitech.2008.10.017

[25] M. Kumar and J. Bijwe, "NAO friction materials with various metal powders: Tribological evaluation on full-scale inertia dynamometer," Wear, vol. 269, no. 11-12, pp. 826-837, 2010. https:// doi.org/10.1016/ j.wear.2010.08.011

[26] M. Kumar and J. Bijwe, "Role of different metallic fillers in non-asbestos organic (NAO) friction composites for controlling sensitivity of coefficient of friction to load and speed," Tribology International, vol. 43, no. 5-6, pp. 965-974, 2010. https:// doi.org/10.1016/j.triboint.2009.12.062

[27] J. Gerlici, T. Lack, and J. Harušinec, "Rail vehicles wheels and brake blocks wear laboratory test stand utilization," Prace naukowe Politechniki Warszawskiej, no. 101, pp. 21-32, 2014.

[28] F. Gojny, M. Wichmann, U. Köpke, B. Fiedler, and K. Schulte, "Carbon nanotube-reinforced epoxycomposites: enhanced stiffness and fracture toughness at low nanotube content," Composites science and technology, vol. 64, no. 15, pp. 2363-2371, 2004. https://doi.org/10.1016/j.compscitech.2004.04.002

[29] A. A. Koval'chuk, V. G. Shevchenko, A. N. Shchegolikhin, P. M. Nedorezova, A. N. Klyamkina, and A. M. Aladyshev, "Effect of carbon nanotube functionalization on the structural and mechanical properties of polypropylene/MWCNT composites," Macromolecules, vol. 41, no. 20, pp. 7536-7542, 2008. https:// doi.org/10.1021/ma801599q

[30] I. Lawrence and U. Paul, "Critical evaluation/ reassessment of (abfm) automotive brake friction materials," Standard Research Journal, 2013.

[31] W. Österle and A. Dmitriev, "Functionality of conventional brake friction materials-perceptions from findings observed at different length scales," Wear, vol. 271, no. 9-10, pp. 2198-2207, 2011. https:// doi.org/10.1016/j.wear.2010.11.035

[32] W. Österle and A. I. Dmitriev, "The role of solid lubricants for brake friction materials," Lubricants, vol. 4, no. 1, p. 5, 2016. https://doi.org/10.3390/ lubricants 4010005

[33] D. Chan and G. Stachowiak, "Review of automotive brake friction materials," Proceedings of the Institution of Mechanical Engineers, Part D: Journal of Au- tomobile Engineering, vol. 218, no. 9, pp. 953-966, 2004. https:/ / doi.org/10.1243/0954407041856773

[34] F.-h. Su, Z.-z. Zhang, and W.-m. Liu, “Mechanical and tribological properties of carbon fabric composites filled with several nano-particulates," Wear, vol. 260 , no. $7-8$, pp. $861-868,2006$. https:// doi.org/10.1016/j.wear.2005.04.015

[35] G. Zhao, I. Hussainova, M. Antonov, Q. Wang, and T. Wang, "Friction and wear of fiber reinforced polyimide composites," Wear, vol. 301, no. 1-2, pp. 122129, 2013. https://doi.org/10.1016/ j.wear.2012.12.019

[36] J. Bijwe, N. Majumdar, and B. Satapathy, "Influence of modified phenolic resins on the fade and recovery behavior of friction materials," Wear, vol. 259, no. 712, pp. 1068-1078, 2005. https:// doi.org/10.1016/ j.wear.2005.01.011

[37] I. Lawrence and U. A. Paul, “Critical evaluation/ reassessment of (abfm) automotive brake friction materials," Stand. Sci. Res. Essays, vol. 1, no. 11, pp. 275-288, 2013.

[38] S. Nagesh, C. Siddaraju, S. Prakash, and M. Ramesh, "Characterization of brake pads by variation in composition of friction materials," Procedia Materials Science, vol. 5, pp. 295-302, 2014. https:// doi.org/10.1016/j.mspro.2014.07.270

[39] A. Beda, P.-L. Taberna, P. Simon, and C. M. Ghimbeu, "Hard carbons derived from green phenolic resins for Na-ion batteries," Carbon, vol. 139, pp. 248-257, 2018. https://doi.org/10.1016/ j.carbon.2018.06.036

[40] G. Akıncıoğlu, S. Akıncıoğlu, H. Öktem, and İ. Uygur, "Wear response of non-asbestos brake pad composites reinforced with walnut shell dust," Journal of the Australian Ceramic Society, pp. 1-12, 2020. https://doi.org/10.1007/s41779-020-00452-6

[41] S. Stephen Bernard and L. Jayakumari, "Effect of rockwool and steel fiber on the friction performance of brake lining materials," Matéria (Rio de Janeiro), vol. 21, no. 3, pp. 656-665, 2016. https:// doi.org/10.1590/S1517-707620160003.0063

[42] O. J. Gbadeyan, "Low friction hybrid nanocomposite material for brake pad application," M-Eng, Durban University of Technology, 2017.

[43] K. Friedrich, Z. Zhang, and A. K. Schlarb, "Effects of various fillers on the sliding wear of polymer composites," Composites Science and Technology, vol. 65, no. 15-16, pp. 2329-2343, 12// 2005, doi: http:// dx.doi.org/10.1016/j.compscitech.2005.05.028.

[45] M. Kim, Y.-B. Park, O. I. Okoli, and C. Zhang, "Processing, characterization, and modeling of carbon nanotube-reinforced multiscale composites," Composites Science and Technology, vol. 69, no. 3, 
pp. 335-342, 2009/03/01/ 2009, doi: https:// doi.org/10.1016/j.compscitech.2008.10.019.

[46] R. Eqra, K. Janghorban, and H. Daneshmanesh, "Mechanical properties and toughening mechanisms of epoxy/graphene nanocomposites," Journal of Polymer Engineering, vol. 35, no. 3, pp. 257-266, 2015. https://doi.org/10.1515/polyeng-2014-0134

[47] H. Unal, K. Esmer, and A. Mimaroglu, “Mechanical, electrical and tribological properties of graphite filled polyamide- 6 composite materials," Journal of Polymer Engineering, vol. 33, no. 4, pp. 351-355, 2013. https:// doi.org/10.1515/polyeng-2013-0043

[48] K. A. Zarasvand and H. Golestanian, “Experimental and numerical determination of compressive mechanical properties of multi-walled carbon nanotube reinforced polymer," Journal of Polymer Engineering, vol. 37, no. 4, pp. 421-431, 2017. https:// doi.org/10.1515/polyeng-2016-0100

[49] X. Dangsheng, “Friction and wear properties of UHMWPE composites reinforced with carbon fiber," Materials letters, vol. 59, no. 2-3, pp. 175-179, 2005. https://doi.org/10.1016/j.matlet.2004.09.011

[50] G. Agarwal, A. Patnaik, and R. Sharma, “Mechanical and thermo-mechanical properties of bi-directional and short carbon fiber reinforced epoxy composites," Journal of Engineering Science and Technology, vol. 9, no. 5, pp. 590-604, 2014.

[51] M. Afolabi, O. Abubakre, S. Lawal, and A. Raji, "Experimental Investigation of Palm kernel shell and Cow bone Reinforced polymer composites for Brake pad Production," International Journal of Chemistry and Materials Research, vol. 3, no. 2, pp. 27-40, 2015. https://doi.org/10.18488/ journal.64/2015.3.2/64.2.27.40

[52] I. M. Dagwa and A. Ibhadode, "Some physical and mechanical properties of asbestos-free experimental brake pad," Journal of Raw Materials Research, vol. 3, no. 2, 2015.

[53] K. Wang, J. Pang, L. Li, S. Zhou, Y. Li, and T. Zhang, "Synthesis of hydrophobic carbon nanotubes/ reduced graphene oxide composite films by flash light irradiation," Frontiers of Chemical Science and Engineering, vol. 12, no. 3, pp. 376-382, 2018. https:/ / doi.org/10.1007/s11705-018-1705-z 